\title{
Transmetatarsal Amputation of Foot
}

National Cancer Institute

\section{Source}

National Cancer Institute. Transmetatarsal Amputation of Foot. NCI Thesaurus. Code C51938.

A surgical procedure in which all or part of the distal foot is removed distal to the tarsometatarsal joint(s). 